\title{
Sport spirituality as an educational innovation (evidenced-based study)
}

\author{
Tamara Olenich ${ }^{1,}$, Vladimir Terarakelyants ${ }^{1}$, Olesya Shestopalova ${ }^{1}$, and Igor Biryukov ${ }^{2}$ \\ ${ }^{1}$ Don State Technical University, 344003, 1, Gagarin square, Rostov-on-Don, Russia \\ ${ }^{2}$ Armavir State Pedagogical University, 352901, 159, St. Rosa Luxemburg, Armavir, Russia
}

\begin{abstract}
The analysis of physical education and sport, its social influence upon the society and spiritual development of the individual, is under consideration. Sport is a specific form of activities, and it develops not only the physical condition of the individual but also it contributes to the spiritual development of the personality. The phenomenon of sport spirituality as a process of imbuing of moral and ethical values during sport performing is investigated. The research hypothesis is that during the sport performance schoolchildren can develop their spirituality and sport is can serve as a useful educational tool to develop ethical and moral values. To verify the research hypothesis, the influence of we surveyed to investigate and describe how sport spirituality arises and function in the particular surrounding. The empirical materials are dedicated to the study of the best practices of implementing spiritual development into the sports during school lessons of physical education. The results showed that sport spirituality serves as a useful educational tool to imbue schoolchildren with moral and ethical values and contribute to the spiritual development of the youth.
\end{abstract}

\section{Introduction}

Modern sport is a complex social phenomenon that performs a lot of social functions, affecting the interests of people of different age groups. Studies showed that in the development of areas of physical culture and sports in modern social sciences we can trace an internal contradiction and paradox, since with the growing need of society in this sphere of life, its understanding and philosophical and conceptual development is behind the growing social demand.

Studies also have shown that the very nature, mission and nature of physical culture and sports is a discursive issue: will they be the prerogative of the sphere of the game or competition, or maybe something more significant for formation and development of physically and spiritually developed personality [1-4].

It is necessary to conduct a holistic study of the problems of physical culture and sport, an analysis of the contradictions that have developed and operate in Russian society between the processes of bodily-physical development, on the one hand, and insufficient definition and understanding of the role of the spiritual components of the characteristics of

\footnotetext{
*Corresponding author: tamara1970@inbox.ru
} 
the sport, on the other. A society cannot be unequivocally healthy, developing corporality and body culture without a certain level of spirituality.

\section{Features of the development of sport spirituality in history}

In the ancient world, the religious and mythological area of public life was close to the sport. The transformation of the ancient sport based on religious and political actions, ceremonies and rituals, especially characteristic of secular-religious and mythological complexes. Nevertheless, the world arrival of national-tribal and religious-mythological variations of sports arose in the context of local, customary customs and traditions.

Historically, the sport was connected with ritual competitions, in which situations of hunting or war in primitive society were symbolically reproduced [5]. The sacred and the secular were one whole in understanding the designation of sports activity in primitive culture and did not know the designation of this phrase in the modern interpretation.

Using the example of ancient Greece and its cultural history, one can see the stages of the birth, flourishing and decay of sport. If we remember that art in the original sense is "techno", that is, skill, then sport here preceded art as a particular area of artistic or other creativity [6]. In any case, based on its social significance in ancient culture, sport was ahead of art, giving it material and content to describe.

As for the times of early Christianity, there was not so much attention to the sport as it was during the ancient period of history, the sport had a specific attitude towards ancient culture, considering it pagan and they condemned various sports, games [7]. However, we note that by the time of the first centuries of Christianity, the sport had already lost that high humanistic content that was characteristic of it in the classical era.

In addition to such metaphors and images that make it possible to understand the essence of the Christian attitude to sports, patristic creations contain specific recommendations for Christians involved in physical education: "... gymnastics schools are much more useful for young men ... they strengthen the health of young people, awaken in them competition and ambition, aimed at developing not only physical, but also mental health. And if these occupations are given without deviating from more important matters, then this is wonderful and not useless. Of the men, some of them can wrestle naked, others can play ball, especially in the open air in the so-called fenindu game; let others be content with traveling around the country and walking around the city" [8].

The religious philosophy of the Middle Ages in Christianity identified the man as an act of creation in the image and likeness of God, where he is free from nature, and in terms of spiritual sin and depends on the Creator [9-11]. Thomas Aquinas thought of the soul as an internal model of the body, and considered their connection possible through and thanks to Divine revelation.

In contrast to the values of the unity of the physical and spiritual principles of the ancient worldview, during the Christian Middle Ages, the thesis of the diversity of the principles of not only material and spiritual but also mind and feeling as components of the body and soul was proclaimed. In the Middle Ages, the human body was considered not only inevitable, but in many respects burdensome for a person using his material existence, since he does not need to give will, but it is necessary to educate him especially in order to free the soul from its unhealthy influence and thereby contribute to its salvation. There was no need to talk about physical development or some harmony and spirituality. The body serves only as instruments for receiving Divine grace.

\section{Modern views on sport and the spiritual development of the individual}


In modern spiritual literature, sport can act as a humanistic basis for the development of a personality, embedded in its very image, reflecting the unity of the physical and spiritual elements of human activity. In this understanding, the principal place is taken by sports (physical) signs of culture, and only then, through the possibility of involving both the individual and the whole society, in sports progress, there is development of the moral components. Since in harmony of the soul with the personal inner world, the principles of spirituality are implemented in sports and sports activities [12].

Philosophy and religion ratify the likelihood of a person's spiritual rebirth, striving for the realization of his ideals, designated life scenarios. In modern Russia, a religious revival is developing, claiming a better position in the spiritualization of the individual. Spiritual practices are introduced into the social life of society, in which some people come to a total distance from worldly affairs, while others are doomed to double existence both in the ordinary and in the "true" world. Achieving "genuine and real" spirituality requires colossal life efforts, as a result of which profound changes in the personality and physical characteristics of a person occur.

The development of the spirituality of a person will be dialogical in the natural process of movement towards integrity through overcoming social and spiritual barriers or contradictions. One of the essential contradictions in the formation and development of a spirituality of the individual pass through the contradictions between the confrontation of the secular and religious orientations of spirituality, as well as among the contradictions within these directions themselves as paradoxes in ethic, aestheticism or dogmatism [13]. Disagreements between secular and religious spirituality are preferably external and are associated with a certain degree of confrontation in the social and cultural sphere [14]. Therefore, sport cannot oppose or complement religion, although it has a cult origin. Familiar to them is the ritualization of action as a culturological phenomenon that affects the entire gamut of perception of the world. Also, standard is the process of overcoming the fear of death, the finiteness of individual existence, through the love of life.

\section{The relationship between sport and moral values}

It is important to note that the morality of an athlete is determined by the moral coordinates established by the social value system. By staging social reality, sport reproduces the complexities and transformations of moral imperatives in the life of an individual. Philosophers almost unanimously argue about the deformation of moral values in the modern era.

Sports ethics, being a form of professional ethics, will be a kind of designation for the norms of public morality. Therefore, it should be considered, from one perspective, as a complex of historically formed norms and rules of behaviour and actions of an athlete that determine his connection with society, the team, his attitude to the process of both wrestling and sports improvement. From a different perspective, sports ethics acts as a circle of universal moral concepts and rules that develop as established theoretical teaching based on general laws in social ethics [15-17].

The question of a person's attitude to his body is, to some extent, ethical, and to some extent, anthropological. In the context of the current biomedical, ecological problematics, it stimulates the search for moral foundations in human life, leads to the problems of substantiating morality in the conditions of ongoing manipulations with ethics, which develop the content of mass moral and moral consciousness thanks to the will of a few, and not through the same form of morality [18].

The sport, as an expression of morality and the improvement of the personality of the Spirit, can be like an indifferent machine of corporeality in the pursuit of achievements and records. With this consideration of a person and the dominance of the "biological 
Frankenstein model", in such a context, the sport will need to be analyzed as a mechanism that supplies competitive external motivation and allows the athlete to use this individual body in the interests of an artificially established measure, that is, the result, victory in the competition [19]. Without a doubt, athletes, coaches, referees and fans view the body, as they perceive corporeality, as a result of a sociocultural process, but what is essential, not humanity in general, but only one strictly defined sociocultural tradition.

The analysis of physical education and sport and the spiritual and social influence upon the society and new parameters of spiritual development of the individual based upon the activities in the sport is of particular importance. All this determines the relevance of research on the problem of the spiritual development of a person in modern society in the context of sports activity, or that social phenomenon that scientists and philosophers have called sport spirituality. While considering sport spirituality, we regard the sport to be the social form in which the culture of spiritual development is in the foreground before the development of the body. Therefore, the present paper is aimed to consider the phenomenon of sport spirituality and its manifestation in practice of Russian comprehensive school to identify how this phenomenon contributes to the spiritual and moral development of the children.

\section{Materials and Methods}

The fundamental basis of this study is an overview of the unique bibliography collected by the researchers, in which the problem of sportosophy is under consideration, including the history and descriptive analysis of this phenomenon in the studies of the tradition and modern researches, carried out during 2010-2020 as well as on the empirical materials.

The empirical materials are dedicated to the study of the best practices of implementing spiritual development into the sports during school lessons of sport. The survey was conducted at secondary schools of 4 municipalities (Besskorbnaya village, Sovetskaya village, Rodnikovskiy village and Pervomayskiy village - located in Krasnodar Krai, a federal subject of the Russian Federation) and including analyses of the questionnaire filled in by the school children aged from 10 to 14 . The total number of school children who were surveyed consists of 171 people.

The research hypothesis is that during the sport performance schoolchildren can develop their spirituality and sport is the unique activity that can be a useful educational tool to develop ethical and moral values. We believe that we will provide evidence that development spirituality trough sports activities can be regarded as a significant educational innovation.

Verifying the research hypothesis, we surveyed to investigate and describe how sport spirituality arises and function in the particular surrounding. We use content analysis of the questionnaires to work out the collected data.

\section{Results and Discussion}

\subsection{Position of the Russian Orthodox Church on physical culture and sports}

Modern Christianity speaks out in defence of an active and healthy lifestyle or physical education. In order to keep pace with the times, many Christian Churches are adapting to comprehensive athletic standards. For example, the Patriarchal Commission for Physical Culture and Sports operates as an official body for the provision and development of church-wide activities in the field of physical culture and sports, as well as for maintaining cooperation of the Russian Orthodox Church with state and local government bodies, 
various institutions and organizations in the field of promoting a healthy lifestyle, supporting physical education and sports (including with bodies for the development of children and youth, student, school sports, mass sports, sports of the highest achievements, professional sports [20].

The Russian Orthodox Church is increasingly showing its position in sports activities. Even though sports activities have not received an official conciliar decree, church ministers initiate various regional competitions, and also actively participate in many sports projects and charity events. In recent years, in various parts of Russia, under the patronage of the Church, annual games, tournaments and sports competitions with the participation of Orthodox youth have begun to gain momentum. Since 2004, the Olympic team has its Orthodox mentor - confessor, and seeing off the Olympic team is accompanied by the blessing of the priests, religious actions and services in churches.

The implementation of sports projects is associated with the disclosure of the potential of psychophysical capabilities in student youth, as well as the approval of the idea of the importance of the harmonious development of their physical, intellectual and spiritual components through the use of physical exercises, various types of physical activity, healthy nutrition, productive use of the work or rest regime [21]. The physical culture and health-improving activity used for this purpose is associated not only with physical exercises, but also affects other cognitive, project-semantic, social and emotionalevaluative aspects.

Within the Orthodox tradition, the direction of sports philosophy has been formed - as an idea of rethinking the social role of sports and physical culture, as well as the influence of sports on the formation of a system of moral and ethical values. In order for young people to begin to form a system of values, it is necessary to familiarize them with the understanding of physical culture as an integral part of the general culture and develop the idea of a comprehensively and harmoniously formed person [22-23]. In this context, the direction of spiritual growth within the framework of sports began to develop, because sports teachers most often use physical culture and sports only to satisfy and develop the physical activity of schoolchildren and much less often as a means for spiritual education, self-education and development, since they do not always have the necessary knowledge, skills and abilities [24].

Man is a psychophysical being, i.e. consists of a soul and a body, not one of these components can be separately human [25]. Often the class is divided into intellectually and physically gifted children. The essence of sport spirituality as a practice is to interest and attract children in various types of activities and forms of work to expand their worldview position, as well as to change, for the better, personal moral and volitional qualities in the process of sports activity.

\subsection{The empirical evidence of positive results of the development of sport spirituality as an educational tool}

Purpose of the research: to identify and study the influence of sport spirituality on the spiritual and moral-ethical development of schoolchildren in the context of non-core education.

Research base: local schools of Besskorbnaya village, Sovetskaya village, Rodnikovskiy village and Pervomayskiy village.

The methods of theoretical knowledge used in this study: 1) analysis; 2) synthesis; 3) generalization; 4) specification; 5) abstraction; 6) statistical method of data processing.

The methods of empirical cognition used in this study: 1) observation; 2) conversation; 3) biographical method; 4) questioning; 5) testing; 6) the method of expert assessments. 
The study of students of secondary schools in the context of the introduction of sport spirituality in the context of non-core education took place in two directions, which reflected the object of experimental work:

1. Working with the management of the school, parents and teachers.

In the process of working with the school administration, teaching staff and parents

students used the following methods of experimental research: conversation, observation, questionnaire method (questionnaire) and the method of expert assessments.

2. In order to diagnose students, we proposed a questionnaire compiled by us for children, parents and teachers, identifying the development of moral and ethical qualities in students. In this questionnaire, questions and statements were given that characterize the possible signs of the development of moral and ethical competence and the general spiritual development of students. In order to identify children in whom, in the process of introducing sport spirituality, the general development of spirituality was noted, the administrative and pedagogical teams of the educational organization, as well as the parents of students, responded to the following statements of the questionnaire to identify the level of formation of moral and ethical qualities of adolescents in the context of sports activity :

- The child has a high academic performance in physical education, which is his favourite school subject.

- The child is happy to attend sports sections, participate in competitions.

- The child prefers to play team games with friends, observing the norms and rules of behaviour in society;

- The child adheres to the generally accepted rules of communication during sports activity: politeness, respect, correctness and goodwill.

- The child does not show interest in bad habits (smoking, alcohol, drugs) and is focused on a healthy lifestyle.

- The child has compassion and patience for those who lag behind his / her level of physical development.

3. Working with students. In the process of working with the students, the following methods of diagnosing psychomotor giftedness were used: conversation, observation, biographical method (the study of a portfolio of sports achievements) and testing.

In order to identify students with a high level of sports activity and interest in sports, we organized a visit to three free lessons on physical culture and three extracurricular sports events, where observation was the primary diagnostic method. At the lessons of sports education and events, the priest met with the children, taking an active part in sports events, thereby motivating a certain contingent of children in the training process. In addition to meetings at physical education lessons, the priest took part in extracurricular sports activities, taking an active part in it with a clear example, thereby motivating a certain contingent of children in the training process, with whom, in the process of physical exercises, a conversation was held in the format of an open dialogue with children.

As a result, students were identified who showed interest in the topics that were raised by the priest during the sports game: caring for the body and mind, sports as a source of competition, winning sports, aggression and determination, healthy lifestyles, sympathy for the losers and infirm.

Additional information about the sports achievements of students included the following research methods: a conversation with coaches who are engaged with students outside of school hours in sports sections; a conversation with physical education teachers about those children who were participants in the meetings.

The empirical research was carried out in the natural conditions of the teaching and educational process in secondary schools of the settlements: Besskorbnaya village, Sovetskaya village, Rodnikovskiy village and Pervomayskiy village - located in Krasnodar. 
The sample consisted of 171 students from different age categories. The age and sex composition of the schoolchildren are shown in the table 1.

Table 1. Age and sex composition of the interviewees

\begin{tabular}{|l|l|l|l|}
\hline Village & Age/Form & Boys & Girls \\
\hline Besskorbnaya & $10 / 4 \mathrm{~A}$ & 12 & 13 \\
village & $14 / 8 \mathrm{~A}$ & 10 & 10 \\
\hline Sovetskaya & $11 / 4 \mathrm{~A}$ & 11 & 12 \\
village & $14 / 8 \mathrm{~A}$ & 10 & 12 \\
\hline Rodnikovskiy & $11 / 4 \mathrm{~A}$ & 10 & 9 \\
villag & $14 / 8 \mathrm{~A}$ & 8 & 11 \\
\hline Pervomayskiy & $10 / 4 \mathrm{~A}$ & 11 & 12 \\
village & $14 / 8 \mathrm{~A}$ & 9 & 11 \\
\hline Total number & 171 & 81 & 90 \\
\hline
\end{tabular}

In the process of experimental research by the method of questioning and based on an oral survey of their parents and teachers, the following number of children was revealed who, as a result of communication with the priest during educational detail and during extracurricular activities, showed an interest in learning a healthy lifestyle, success in improving socialization and to thinking about victory, tolerance towards less physically developed students:

a) out of 171 students, according to the results of the survey, 15 children were identified who demonstrated a high level of interest in the development of moral and moral qualities and interest in continuing meetings with the priest in the process of sports activities;

b) out of 171 students, $45 \%$ of the respondents addressed their interest in moral and ethical standards, addressing questions to their parents and teachers;

c) out of 171 students, $57 \%$ of the respondents stated that in the process of sports activity, the manifestation of humanism, patience and compassion for less developed physically peers is necessary.

According to the results of the study, the surveyed schoolchildren, their parents and teachers offered their views on the implementation of the idea of sport spirituality in the educational space of the school.

Thus, sport spirituality as an educational innovation manifested itself as a set of specific communicative techniques associated with mental processes of children (cognitive and emotional-volitional), such as thinking, memory, attention, feelings, which in the process of sports activities were aimed at developing interest in a healthy lifestyle and adherence to social rules in the process of sports.

We think that the obtained results can be put into the development of the next educational strategy based on the education of sport spirituality. The leading positions of the development of spiritual and sports education will include:

1. Determination of the goal and objectives of a particular lesson.

2. Identification of how and where the learning process should take place, with the participation of a teacher and a priest.

3. Ways and methods of action to create the infrastructure of the new educational process and the implementation of the training itself.

4. Definition and formulation of expected results and their impact on social realities.

Based on the survey of children and parents who took part in the survey, the practical implementation of sport spirituality can include, in addition to meetings in the classroom and extracurricular sports activities of the school, the development of spiritual organizational ties, further carrying out single tournaments in various sports. For example, the "Christmas" football cup can be held during the winter holidays, thereby organizing the activities of students during the holidays if there is any sports complex or playground near the temple where you can carry out these activities. In particular, after the Sunday Liturgy, 
multifunctional training sessions can be organized for children, and specialized health groups can be conducted for older people.

Besides, the strategy can include cooperation with various sports federations and organizations, mutual communication with the coaching team strengthens understanding and contributes to the fruitfulness of the mission, where prayers are served before competitions of various levels, conversations are held, athletes take part in religious processions and organizing order in the temple during the holidays. Also impressive is the form of work as a joint meeting with a famous athlete or coach, who will share not only their life examples and secrets of skill but also their view of the world around them, a meeting with God.

During outdoor sports events, it is possible to organize short-term excursions to local temples and historical sites. Thus, favourable conditions are created for increasing interest and independent study of spiritual components, and through this, an increase in moralvolitional, motivational factors.

\subsection{Methodology for monitoring spiritual and moral development during sport performance}

Based on the results of the survey and the content-analyses of the questionnaires filled in by the children, parents and the teachers, the present study makes several noteworthy contributions to the methodology for monitoring the spiritual and moral development during sport performance:

- monitoring due to the delayed results of spiritual and moral development, upbringing and socialization of schoolchildren, it is advisable to build, on the one hand, on the tracking of the procedural side of the life of school communities (activities, communication, activities) and educational activities of teachers, and on the other, on the study of individual success school graduates;

- when developing and implementing a monitoring program, it is necessary to combine the general goals and objectives of spiritual and moral development, education and socialization of students, set by the Federal State Educational Standard, and specific ones, determined by the social environment of the school, traditions, way of the educational organization and other circumstances;

- a set of monitoring measures is proposed to be oriented, first of all, not to control the activities of teachers, but to improve their activities aimed at ensuring the processes of spiritual and moral development at the lessons of physical education;

- monitoring should offer extremely simple, transparent, formalized diagnostic procedures;

- the proposed monitoring should not significantly increase the volume of work, introduce additional difficulties, accountability, worsen the situation in the daily practice of teachers who, through their activities, ensure the implementation of the tasks of spiritual and moral development of students;

- it is not advisable to assign exclusive responsibility for the spiritual and moral development only to the teaching staff of the school, since the experiment has shown that to involve the priests to the lessons of sport and extracurricular activities of the sort;

- in the course of monitoring, it is essential to proceed from the factual incomparability of the results of spiritual and moral development in different schools, student communities and concerning different students (school or a student can only be compared with themselves);

- the work provides for a gradual improvement of the monitoring methodology (it is assumed that this tool is gradually introduced into the practice of educational organizations). 
These findings enhance our understanding that the toolkit for monitoring the spiritual and moral development has to include the following elements:

- professional and public examination of plans and programs of spiritual and moral development or their element in the traditional courses for adherence to the requirements of the Federal State Educational Standard and taking into account the specifics of the general educational organization (socio-cultural environment, school life, requests from parents and the public, available resources);

- periodic monitoring of the implementation of plans for sport activities during which it is possible to provide the spiritual and moral development of students;

- professional and public examination of reports on the provision of spiritual and moral development for the analysis and reflection of the changes that have occurred due to the activities of the sport teachers in the life of the school, pupil groups, and individual pupils.

The findings from this study make several contributions to the indicators of the effectiveness of an educational organization in terms of spiritual and moral development. The first criterion is the degree of the provision in the educational organization of the life and health of students, the formation of a healthy and safe lifestyle, expressed in the following indicators:

- the level of awareness of visiting sports clubs, the regularity of physical education;

- the realistic number and sufficiency of measures to ensure the rational organization of the educational process and the educational environment, the organization of physical culture, sports and health-improving work, preventive work, the formation of a conscious attitude towards their health, stable ideas about health and a healthy lifestyle, the formation of students' assessment skills own functional state, the formation of students' competencies in the preparation and implementation of a rational regime of the day and rest;

The second criterion is the degree of the provision in the educational organization of positive interpersonal relations of students, expressed in the following indicators:

- the level of awareness about the state of interpersonal relations in student communities (specific problems of interpersonal relations among schoolchildren), the frequency of fixing the dynamics of the state of interpersonal relations in student classes;

- consistency of sport activities that ensure positive interpersonal relationships among schoolchildren.

The third criterion is the degree of assistance to pupils in the development of additional education programs is expressed in the following indicators:

- the degree of correctness of the principles and methodological rules for the implementation of the tasks of educating pupils;

- realistic number and sufficiency of events (topics, form and content of which are adequate to the tasks of educating students);

- coordination of educational activities with the parents of students, the involvement of parents in the organization of events.

\section{Conclusions}

Based on the analysis of theoretical approaches to the development of sport spirituality and the practical experience of Russian schools and the Russian Orthodox Church in this area, we can assert that the hypotheses we put forward in the research process were confirmed: during the sport performance schoolchildren can develop their spirituality and sport is the great activity that can be a useful educational tool to develop ethical and moral values.

An essential practical result is also the fact that the introduction of sport spirituality into the practical activities of school institutions potentially contributes to: 
- familiarizing people who are involved in physical education and sports regularly with Orthodox culture and traditions;

- increasing interest in physical education and sports among schoolchildren who have an Orthodox worldview, but do not pay attention to physical activity;

- attracting a large number of people who are still in search of the right path, thanks to the support of the clergy in an informal setting;

- an increase in the number of quitting smoking, alcohol and drugs among schoolchildren, thanks to an integrated approach to personality;

- creation of optimal conditions for versatile psychophysical training and passing the standards of the Russian Sport;

- the formation of an Orthodox worldview and a healthy lifestyle among the residents of the Krasnodar Territory, the establishment of social contacts, as well as joint leisure and active recreation.

Thus, sport spirituality is aimed at realizing the importance of a healthy lifestyle in life and a person's worldview, openness and desire for cooperation with many sports organizations and associations, and, consequently, the attention of the clergy to this area and the training of specialized personnel. There is an increase in the educational impact on the personality of a young person, as well as educational measures about the national, cultural characteristics of Russian society. We recommend to use the education of strongwilled qualities, mentoring through sports, spiritual practices - for the spiritual and moral education of youth.

\section{References}

1. R. J. Schinkea, A. T. Blodgetta, T. V. Rybac, S. Fu Kaob, T. R. F. Middletond, PSE, 42, 58-65 (2019) doi: 10.1016/j.psychsport.2018.09.004.

2. Y.-E. Noh, S. Shahdan, PSE, 46, 101603 (2020) doi: 10.1016/j.psychsport.2019.101603.

3. M. Sarkar, D. M. Hill, Andrew Parker, PSE, 17, 48-55 (2015) doi: 10.1016/j.psychsport.2014.09.001.

4. R. E. Rhodes, D. McEwan, A. L. Rebar, PSE, 42, 100-109 (2019) doi: 10.1016/j.psychsport.2018.11.010.

5. M. R. Beauchamp, K.n L. Crawford, B. Jackson PSE, 42, 110-117 (2019) doi: 10.1016/j.psychsport.2018.11.009.

6. H. Qurban, H. Siddique, J. Wang, T. Morris, JHP, 1, 27-40 (2018) doi: 10.14302/issn.2644-1101.jhp-18-2467/

7. J. Zalewska, PSR, 1(205), 65-84 (2019) doi: 10.26412/psr205.05.

8. I. Jirásek, Quest, 67(3), 290-299 (2015) doi: 10.1080/00336297.2015.1048373.

9. N. J. Watson, A. Parker (Eds.), Sports and Christianity: Historical and contemporary perspectives (London, UK: Routledge, 2012).

10. M. Bednář, Acta Facultatis Educationis Physicae, 51(2), 75-84(2011)

11. W. Burkert, Greek religion: Archaic and classical rans (Oxford, UK: Blackw, 2004)

12. R. Cipriani, Implicit Religion, 15(2), 139-151(2012)

13. M. Collins, Implicit Religion, 17(2), 139-163 (2014) doi: 10.1558/imre.v17i2.139.

14. H. Davis, E. Serventi, SEPR, 13(2), 55-56 (2017)

15. T. J. Egli, L. F. Fisher, N. Gentner, Sport Psychologist, 28(4), 394-405 (2014) doi: 10.1123/tsp.2013-0082. 
16. L. Harvey, Brief theology of sport (London, UK: SCM Press, 2012)

17. R. A. Hutch, Practical Theology, 5(2), 131-152 (2012) doi: 10.1558/prth.v5i2.131.

18. I. Jirásek, Implicit Religion, 16(2), 191-201 (2013)

19. I. Jirásek, Sport, Ethics and Philosophy, 12(1), 30-49 (2018) doi: 10.1080/17511321.2017.1307266.

20. S. Kretchmar, N. J. Watson, Sport, Ethics \& Philosophy, 12(1), 70-80 (2018) doi: 10.1080/17511321.2017.1291713.

21. R. Meyer, M. R. Umstattd Meyer, IJSS, 8(1), 51-67 (2017)

22. R. Meyer, C. J. Wynveen, A. R. Gallucci, IRSS, 52, 631-647 (2015)

23. Parker, N. J. Watson, SWC, 21(3), 223-238 (2015) doi: 10.3366/swc.2015.0125.

24. M. Proios, Trends in Sport Sciences, 24(3), 117-122 (2017)

25. N. Watson, JRPC, 23(2), 182-200 (2011) 